\section{THE MEDICAL PRACTITIONERS OF CARLISLE.}

From the reply of these gentlemen to the recent statements of the governors of the Cumberland Infirmary, we derive the following remarks. The medical body say,-

That their views, in relation to the management of the hospital, were founded on a thorough knowledge of the professional circumstances of the place, and on an earnest desire to promote not only the best interests of the institution, but a friendly intercourse, and a higher tone of professional feeling among the practitioners resident in Carlisle. They were fully aware that the propositions they made were uncommon; but they were not ignorant that the usual course of proceed. ing, in the appointment of medical officers to public charities, is often attended by consequences equally injurious to the main purpose contemplated, and to the general character of the profession to which they belong; in fact, that intrigue and private influence often supersede the more solid claims to such distinctions, and engender feelings of hostility and dissension.

Actuated by these sentiments, they were at much pains to impress their views upon the minds of the governors. Their numbers were such as torender the proposed arrangement perfectly practicable. They brought forward the practice of the Whitehaven Infirmary, and that of the clinical wards in almost every hospital attached to the medical schools in this country, as examples of the system they proposed. It was their express desire to co-operate with each other in carrying out the object of the institution; they were severally requested to say, "whether they would give their support to it gratuitously." They conceive that service of the kind is too lightly esteemed when those who perform it without compensation are denied the privilege of stipulating the terms of their dity. That the governors should have been so far misled by a fancied analogy between the circumstances of a public hospital and those of a pRIVATE family, as to infer the existence of a MIORAL obligation for their thus rejecting the terms proposed, is at least remarkable when contrasted with the considerations above referred to, and with the means adopted for carrying out their design. It is quite clear that this supposition has led them to prejudge the competency of the majority of the established practitioners in Carlisle; and, putting the institution at the same time on half service, to prefer before men of several years' standing in the profession, a gentleman whose legal qualification to practise bears so recent a date as that of OCTO BER 29, 1841.

\footnotetext{
(Signed)

Richard Oliver, M.D., Chairman. January, 1842.
}

EXPLANATION FROM DR. H. BIRD.

\section{To the Editor of The LANCET.}

Sir,-I confess it was with much surprise I found my name gracing the columns of the last number of your Journal (p. 520), particularly as I am entirely ignorant to whom I am indebted for the honour of introdncing me to the readers of your useful and independent Periodical. And, Sir, as perfect impartiality has ever been the pilot that guided that Periodical through the stormy course of medical warfare, $I$ have no doubt you will afford me space in your columns, whilst I explain the conduct that has drawn forth the censure of my anonymous opponent. Wishing, some months back, to graduate in medicine, after practising for twenty years as a general practitioner in this town, $I$ instituted inquiries as to the possibility of enrolling myself among the honoured few, who are fortunate enough to obtain admission inside the hallowed portals of that seat of science in Pall-mall ; but found I might as well endeavour to infuse a spirit of disinterestedness and liberality amongst its inmates, as attempt to cross the barrier, formed only to inclose within its walls the polite, elite, and aristocratical in the profession, whether combined with science, wisdom, and learning, the ensuing session, I trust, shall test: I therefore came to the determination of graduating in the university of Geisen, in Germany; and when, after a couple of months' absence for that purpose, I returned to Chelmsford, my indignation was raised and excited, by finding the most false and foul-mouthed reports set on foot, commenting on the object of $\mathrm{my}$ journey, the respectability of $\mathrm{my}$ qualification, the certainty of my surrendering the rights and emoluments accruing to me as a general practitioner, all calculated to do me serious injury in the eyes of my patients, and injure me in every possible way. I confess I did insert, perhaps hastily and inconsiderately, my return, and explanation of the grounds on which, for the future, I intended to practise, viz., not to resign my general practice, or to confine myself to what is termed a pure physician. This, Sir, has been my fault (if such you view it); but believe me, any unworthy or dishonourable motive, in giving insertion to my resolution, was far indeed from my mind: I have never done anything yet, during a long period of practice, in the slightest degree, derogatory to the honour of my profession; and I defy my brother practitioners in this town and neighbourhood to adduce an instance. Which defiance shall be extended to the gentleman (whoever he may be) so ready to drag my name before the profession, but slow, in deed, to correct me in my fault in private, as one professional neighbour should to another. Again, believe me, if $I$ have erred in transgressing the honourable rules of a profession 